\title{
Takagi-Sugeno Fuzzy Observer for a Switching Bioprocess: Sector Nonlinearity Approach
}

\author{
Enrique J. Herrera-López ${ }^{1}$ Bernardino Castillo-Toledo², \\ Jesús Ramírez-Córdova ${ }^{1}$ and Eugénio C. Ferreira ${ }^{3}$ \\ ${ }^{1}$ Centro de Investigación y Asistencia en Tecnología y Diseño del Estado de Jalisco \\ ${ }^{2}$ Centro de Investigación y de Estudios Avanzados del I.P.N, Unidad Guadalajara \\ Institute for Biotechnology and Bioengineering, Universidade do Minho, Braga \\ 1,2México, 3 Portugal
}

\section{Introduction}

In a bioprocess it is desired to produce high amounts of biomass or metabolites such as vitamins, antibiotics, and ethanol, among others. The measurement of biological parameters as the cell, by-product concentrations and the specific growth rate are essential to the successful monitoring and control of bioprocesses (Horiuchi \& Kishimoto, 1998). Adequate control of the fermentation process reduces production costs and increases the yield while at the same time achieve the quality of the desired product (Yamuna \& Ramachandra, 1999). Nevertheless, the lack of cheap and reliable sensors providing online measurements of the biological state variables has hampered the application of automatic control to bioprocesses (Bastin \& Dochain, 1990). This situation encourages the searching of new software sensors in bioprocesses.

A state observer is used to reconstruct, at least partially the state variables of the process. Two classes of state observers or software sensors for (bio)chemical processes can be found in the literature (Dochain, 2003). A first class of observers called asymptotic observers, is based on the idea that the uncertainty in bioprocess models is located in the process kinetics models. A second class is based on the perfect knowledge of the model structure (Luenberger, Kalman observers and nonlinear observers). Different applications of state observers in bioprocess are reported in the literature (Cazzador \& Lubenova, 1995; Farza et al., 2000; Guay \& Zhang, 2002; Lubenova et al., 2003; Oliveira et al., 2002; Soh \& Cao, 1999; Veloso et al., 2007).

Fuzzy logic has become popular in the recent years, due to the fact that it is possible to add human expertise to the process. Nevertheless, in the case where the nonlinear model and all the parameters of a process are known, a fuzzy system may be used. A first approach can be done using the Takagi-Sugeno fuzzy model (Takagi \& Sugeno, 1985), where the consequent part of the fuzzy rule is replaced by linear systems. This can be attained, for example, by linearizing the model around operational points, getting local linear representation of the nonlinear system. 
Another way to obtain a model can be achieved using the method of sector nonlinearities, which allows the construction of an exact fuzzy model from the original nonlinear system by means of linear subsystems (Tanaka \& Wang, 2001). From this exact model, fuzzy state observers and fuzzy controllers may be designed based on the linear subsystems. Different fuzzy logic applications to bioprocesses can be found in the scientific literature (Genovesi et al., 1999, Ascencio et al., 2004; Karakazu et al., 2006). In this chapter a Takagi-Sugeno fuzzy observer based on sector nonlinearities is proposed and applied to a continuous nonlinear baker's yeast fermentation process. The observer gains are calculated using linear matrix inequalities. An interesting feature of this model is that it can be divided in two models: a respiro-fermentative $(R F)$ model with ethanol production and a respirative $(R)$ model with ethanol consumption. The model can switch to the $R F-R-R F$ model depending on whether the yeasts are producing or consuming ethanol.

\section{Fuzzy Systems Preliminaries}

A nonlinear system may be represented by linear subsystems called Takagi-Sugeno, (figure 1). The Takagi-Sugeno fuzzy models are used to represent nonlinear dynamics by means of a set of IF-THEN rules. The consequent parts of the rules are local linear systems obtained from specific information about the original nonlinear plant.

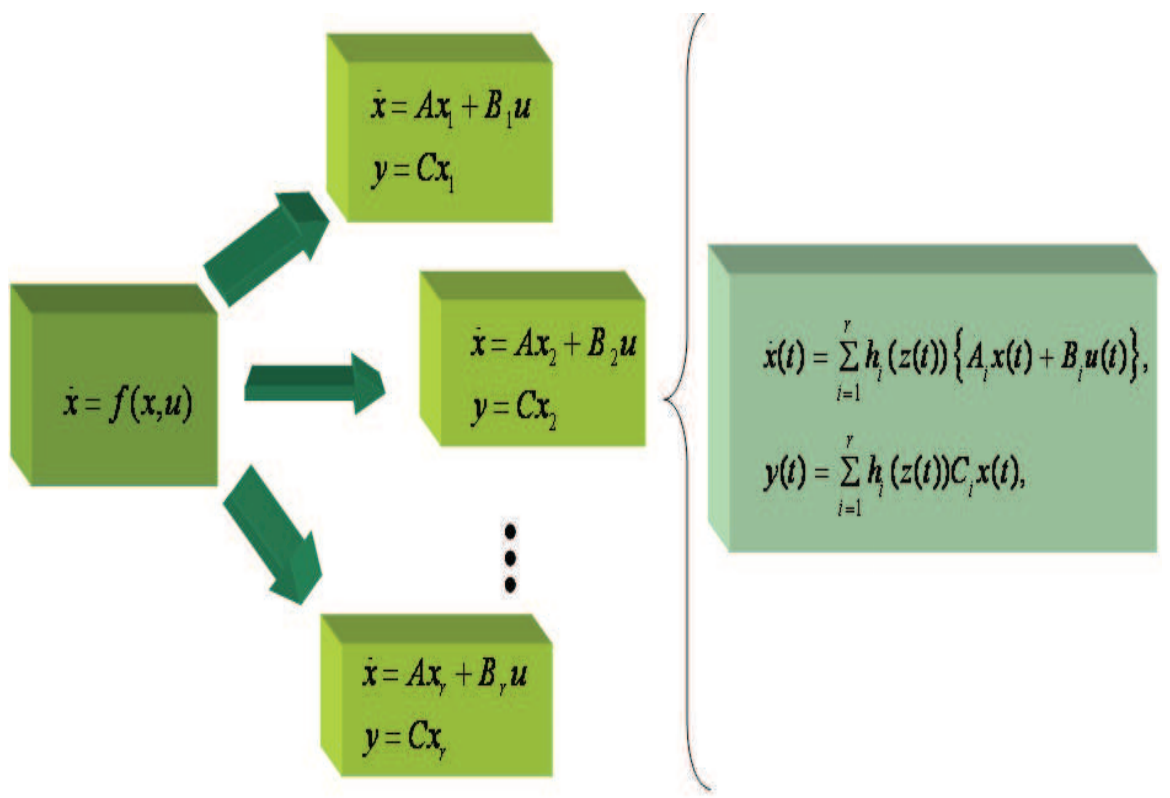

Fig. 1 Takagi-Sugeno representation for a nonlinear system

The $i$ th rule of a continuous fuzzy model has the following form:

\section{Model Rule i:}

If $z_{1}(t)$ is $\varphi_{i 1}$ and $\ldots$ and $z_{p}(t)$ is $\varphi_{i p}$. 


$$
\text { THEN }\left\{\begin{array}{l}
\dot{x}(t)=A_{i} x(t)+B_{i} u(t) \\
y(t)=C_{i} x(t)
\end{array} \quad i=1,2,3, \ldots ., r,\right.
$$

where $\varphi_{i j}$ is a fuzzy set and $r$ is the number of rules in the fuzzy model; $x(t) \in \mathfrak{R}^{\text {n }}$ is the state vector, $u(t) \in \mathfrak{R}^{m}$ is the input vector, $y(t) \in \mathfrak{R}^{\natural}$ is the output vector, $A_{i} \in \mathfrak{R}^{\mathfrak{h} \times m}, B_{i} \in \mathfrak{R}^{\mathrm{h} \times \mathrm{m}}$, and $C_{i} \in \mathfrak{R}^{q x n}$ are suitable matrices, and $z(t)=\left[z_{1}(t), \ldots, z_{p}(t)\right]$ is a known vector of premise variables which may coincide or partially depend on the state $x(t)$.

Given a pair of $(x(t), u(t))$ and using a singleton fuzzifier, product inference and center of gravity defuzzifier, the aggregated Takagi-Sugeno fuzzy model can be inferred as:

$$
\begin{aligned}
& \dot{x}(t)=\sum_{i=1}^{r} h_{i}(z(t))\left\{A_{i} x(t)+B_{i} u(t)\right\}, \\
& y(t)=\sum_{i=1}^{r} h_{i}(z(t)) C_{i} x(t),
\end{aligned}
$$

where

$$
h_{i}(z(t))=\frac{\prod_{j=1}^{p} \varphi_{i j}\left(z_{j}(t)\right)}{\sum_{i=1}^{r} \prod_{j=1}^{p} \varphi_{i j}\left(z_{j}(t)\right)}
$$

for all $t$. The term $\varphi_{i j}\left(z_{j}(t)\right)$ is the membership value of $z_{j}(t)$ in $\varphi_{i j}$. Since

$$
\begin{gathered}
\prod_{j=1}^{p} \varphi_{i j}\left(z_{j}(t)\right) \geq 0 \text { and } \sum_{i=1}^{r} \prod_{j=1}^{p} \varphi_{i j}\left(z_{j}(t)\right)>0, \quad i=1, \ldots, r \\
h_{i}(z(t)) \geq 0 \text { and } \sum_{i=1}^{r} h_{i}(z(t))=1, \quad i=1, \ldots r
\end{gathered}
$$

for all $t$.

\subsection{Sector Nonlinearity}

A nonlinear system may also be represented by sectors (Tanaka \& Wang, 2001). Consider a nonlinear system given by $\dot{x}(t)=f(x(t))$ where $f(0)=0$. A global sector is found when $\dot{x}(t)=f(x(t)) \in\left[s_{1} s_{2}\right] x(t)$, where $s_{1} x(t)$ and $s_{2} x(t)$ are lines as shown in figure 2. A global sector guarantees an exact fuzzy representation for the nonlinear model. Some times it is difficult to find global sectors, in that case it is possible to find a local sector bounded by the region $-a<x(t)<a$, as shown in figure 3 . 


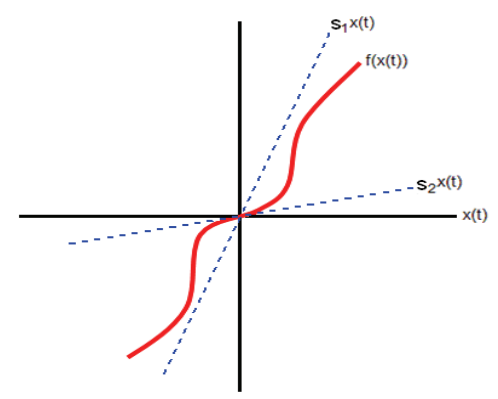

Fig. 2 Global sector

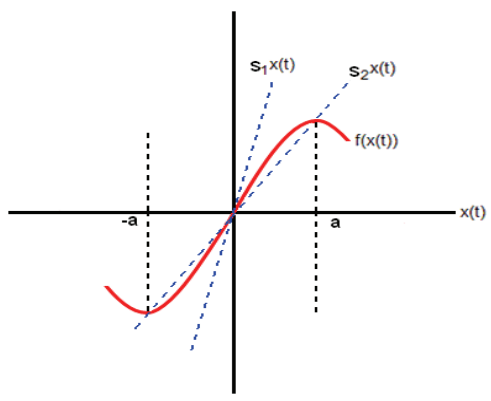

Fig. 3 Local sector

\subsection{Fuzzy Observer}

The state of a system is not always fully available, so it is necessary to use an observer to reconstruct, at least partially the states variables of the process. This requires to satisfy the condition

$$
\lim _{t \rightarrow 0}(x(t)-\hat{x}(t))=0
$$

where $\hat{x}(t)$ denotes the state vector estimated by the fuzzy observer. There are two cases for fuzzy observers design depending on whether or not $z(t)$ depends on the state variables estimated by a fuzzy observer (Tanaka \& Wang, 2001). Given the Takagi-Sugeno fuzzy model (1), the $i$ th rule of a continuous fuzzy observer can be constructed as:

\section{Observer Rule $i$}

If $z_{1}(t)$ is $\varphi_{i 1}$ and $\ldots$ and $z_{p}(t)$ is $\varphi_{i p}$.

$$
\text { THEN }\left\{\begin{array}{l}
\hat{\dot{x}}=\sum_{i=1}^{r} h_{i}(z(t))\left\{A_{i} \hat{x}(t)+B_{i} u(t)+K_{i}(y(t)-\hat{y}(t))\right\}, \\
\hat{y}(t)=h_{i}(z(t)) C_{i} \hat{x}(t) .
\end{array}\right.
$$

where $K_{i}$ is the observer gain and $\hat{y}(t)$ is the fuzzy observer output for the $i$ th subsystem. If $z(t)$ depends on the estimated state variables, the observer consequent part takes the following form:

$$
\text { THEN }\left\{\begin{array}{l}
\hat{\dot{x}}=\sum_{i=1}^{r} h_{i}(\hat{z}(t))\left\{A_{i} \hat{x}(t)+B_{i} u(t)+K_{i}(y(t)-\hat{y}(t))\right\}, \\
\hat{y}(t)=h_{i}(\hat{z}(t)) C_{i} \hat{x}(t) .
\end{array}\right.
$$

It is possible to calculate the observer gains from the solution $X, N_{i}$ of the following inequalities (Tanaka \& Wang, 2001). 


$$
\begin{aligned}
& X>0 \\
& -A_{i}^{T} X-X A_{i}+C_{i}^{T} N_{i}^{T}+N_{i} C_{i}-2 \alpha X>0 \\
& -A_{i}^{T} X-X A_{i}-A_{j}^{T} X-X A_{j}+C_{j}^{T} N_{i}^{T}+N_{i} C_{j}+C_{i}^{T} N_{j}^{T}+N_{j} C_{i}-4 \alpha X \geq 0 \\
& \quad i<j \text { s.t. } h_{i} \cap h_{j} \neq \varnothing
\end{aligned}
$$

where $A_{i}$ is the state matrix and $C_{i}$ is the output matrix. The decay rate $(\alpha)$ is related with the observer speed response. The inequalities (8) can be converted to linear matrix inequalities by means of Shur's complement (Braatz \& VanAntwerp, 2000). The condition $i<j$ s.t. $h_{i} \cap h_{j}$ $\neq \varnothing$ means that inequalities (8) holds for all $i<j$ excepting $h_{i} z(t) \cdot h_{j} z(t)=0$ for all $z(t)$. The observer gain $K_{i}$ and the common positive definite matrix $P$ can be obtained by means of

$$
P=X^{-1}, \quad K_{i}=X^{-1} N_{i}
$$

The fermentative mathematical model will now be described.

\section{Fermentation Mathematical Model}

The Saccharomyces cerevisiae yeast may grow on glucose following three metabolic pathways (Sonnleitner \& Käpelli, 1986).

1.- Oxidative growth on glucose, in presence of oxygen $\left(\mathrm{O}_{2}\right)$ the glucose $(S)$ is consumed to produce biomass $(\mathrm{X})$ and carbon dioxide $\left(\mathrm{CO}_{2}\right)$.

$$
\mathrm{S}+\mathrm{O}_{2} \stackrel{\mu_{s}^{o}}{\longrightarrow} \mathrm{X}+\mathrm{CO}_{2}
$$

2.- Fermentative growth on glucose, in absence of oxygen the substrate is used to produce biomass, carbon dioxide and mainly ethanol $(E)$.

$$
S \stackrel{\mu_{s}^{r}}{\longrightarrow} X+\mathrm{CO}_{2}+E
$$

3.- Oxidative growth on Ethanol, the ethanol produced by the fermentative pathway may be consumed in presence of oxygen producing biomass and carbon dioxide.

$$
\mathrm{E}+\mathrm{O}_{2} \stackrel{\mu_{e}^{o}}{\longrightarrow} \mathrm{X}+\mathrm{CO}_{2}
$$

\subsection{The Respiro-Fermentative and Respirative Fermentation Models}

A continuous baker's yeast culture can be represented by the following set of differential equations 


$$
\begin{aligned}
& \dot{x}_{1}=\left(\mu_{s}^{o}+\mu_{s}^{r}+\mu_{e}^{o}\right) x_{1}-D x_{1} \\
& \dot{x}_{2}=\left(-k_{1} \mu_{s}^{o}-k_{2} \mu_{s}^{r}\right) x_{1}-D x_{2}+D s_{i n} \\
& \dot{x}_{3}=\left(k_{3} \mu_{s}^{r}-k_{4} \mu_{e}^{o}\right) x_{1}-D x_{3} \\
& \dot{x}_{4}=\left(-k_{5} \mu_{s}^{o}-k_{6} \mu_{e}^{o}\right) x_{1}-D x_{4}+\text { OTR }
\end{aligned}
$$

where the variables of model (13) are shown in table 1.

\begin{tabular}{c|c}
\hline Variables & Units \\
\hline$x_{1}=$ Biomass concentration & $\mathrm{g} / \mathrm{l}$ \\
$x_{2}=$ Glucose concentration & $\mathrm{g} / \mathrm{l}$ \\
$x_{3}=$ Ethanol concentration & $\mathrm{g} / \mathrm{l}$ \\
$x_{4}=$ Dissolved oxygen concentration & $\mathrm{mgl}$ \\
$D=$ Dilution rate & $1 / \mathrm{h}$ \\
$S_{\text {in }}=$ Substrate concentration feed & $\mathrm{g} / \mathrm{l}$ \\
OTR $=K_{\mathrm{L}} a\left(C\right.$ sat $\left.-x_{4}\right)=$ Oxygen transfer rate & $\mathrm{mg} / \mathrm{h}$ \\
$\mu_{s}^{o}=$ Specific growth rate (oxidative growth on glucose) & $1 / \mathrm{h}$ \\
$\mu_{s}^{r}=$ Specific growth rate (fermentative growth on glucose) & $1 / \mathrm{h}$ \\
$\mu_{e}^{o}=$ Specific growth rate (oxidative growth on ethanol) & $1 / \mathrm{h}$ \\
$k_{1}, k_{2}, k_{3}, k_{4}, k_{5}, k_{6}=$ yield coefficients &
\end{tabular}

Table 1. Variables used in the baker's yeast model (13)

The oxygen transfer rate is given by OTR $=K_{L} a\left(C^{\text {sat }}-x_{4}\right)$ which may be split in two terms, one that is constant and another one that depend on the dissolved oxygen.

$$
\begin{aligned}
& -K_{L} a x_{4} \\
& K_{L} a C^{s a t}
\end{aligned}
$$

Pormeleau (1990) suggested a reformulation of model (13) using two partial models: a respiro-fermentative partial model $(R F)$ with ethanol production and a respirative partial model $(R)$ with ethanol consumption. With this reformulation a split process model is obtained, switching from the $R F$ partial model to the $R$ partial model and vice versa depending on whether the system is consuming or producing ethanol. To precise these ideas, consider a nonlinear system described by model (16-17), which can be written as

$$
\begin{aligned}
& \dot{x}(t)=f_{i}(x(t))+B u(t)+d, \quad i=1,2 \\
& y(t)=h(x(t))
\end{aligned}
$$


where $f_{i}(x(t))$ describe both the $R F$ and $R$ partial models, namely

$$
f_{1}=\left[\begin{array}{c}
\left(\mu_{s_{-} R F}^{o}+\mu_{s_{-} R F}^{r}\right) x_{1}-D x_{1} \\
\left(-k_{1} \mu_{s_{-} R F}^{o}-k_{2} \mu_{s_{-} R F}^{r}\right) x_{1}-D x_{2} \\
k_{3} \mu_{s_{-} R F}^{r} x_{1}-D x_{3} \\
-k_{5} \mu_{s_{-} R F}^{o} x_{1}-D x_{4}-K_{L} a x_{4}
\end{array}\right]:=f_{R F}
$$

and for the $R$ model

$$
f_{2}=\left[\begin{array}{c}
\left(\mu_{s_{-} R}^{o}+\mu_{e_{-} R}^{o}\right) x_{1}-D x_{1} \\
-k_{1} \mu_{s_{-} R}^{o} x_{1}-D x_{2} \\
-k_{4} \mu_{e_{-} R}^{o} x_{1}-D x_{3} \\
\left(-k_{5} \mu_{s_{-} R}^{o}-k_{6} \mu_{e_{-} R}^{o}\right) x_{1}-D x_{4}-K_{L} a x_{4}
\end{array}\right]:=f_{R}
$$

The input vector and the manipulated variable are given by

$$
\begin{aligned}
& B=[0, D, 0,0]^{\mathrm{T}}, \\
& u(t)=S_{\text {in }}
\end{aligned}
$$

where $T$ is the input vector transpose. As already said, OTR rate was divided in two terms, the first one $-K_{L} a x_{4}(14)$ was included in $f_{R F}(18)$ and $f_{R}$ matrices (19); the second term $K_{L} a C^{\text {sat }}$ (15), is taken as a known and constant perturbation $(d)$ given by

$$
d=\left[0,0,0, K_{L} a C^{s a t}\right]^{T}
$$

In the RF partial model, the metabolic pathways oxidative growth on glucose (10) and fermentative growth on glucose (11) are present, therefore ethanol is produced. The specific growth rates for the $R F$ partial model are given by:

$$
\begin{aligned}
& \mu_{s_{-} R F}^{o}=Y_{O_{2}}\left(q_{o}^{\max } \frac{x_{4}}{K_{o}+x_{4}}\right) \\
& \mu_{s_{-} R F}^{r}=Y_{r}\left(q_{s}^{\max } \frac{x_{2}}{K_{s}+x_{2}}-q_{c}^{\max } \frac{x_{4}}{K_{o}+x_{4}} \frac{Y_{O 2}}{Y_{o}}\right)
\end{aligned}
$$

In the $R$ partial model, the pathway oxidative growth on glucose (10) is also present; however, the specific growth rate is now given by: 


$$
\mu_{s_{-} R}^{o}=Y_{o}\left(q_{s}^{\max } \frac{x_{2}}{K_{s}+x_{2}}\right)
$$

The oxidative growth on ethanol (12) for the $R$ partial model depends on,

$$
\mu_{\mathrm{e}_{-} \mathrm{R}}^{\mathrm{o}}= \begin{cases}q_{e_{1}} & \text { if } q_{e_{1}}<q_{e_{2}} \\ q_{e_{2}} & \text { if } q_{e_{1}} \geq q_{e_{2}}\end{cases}
$$

where

$$
\begin{gathered}
q_{e_{1}}=Y_{e} q_{e}^{\max } \frac{x_{3}}{K_{e}+x_{3}} \frac{K_{i}}{K_{i}+x_{2}} \\
q_{e_{2}}=Y_{O_{2} e}\left(q_{o}^{\max } \frac{x_{4}}{K_{O}+x_{4}}-\frac{Y_{o}}{Y_{O_{2}}}\left(q_{s}^{\max } \frac{x_{2}}{K_{s}+x_{2}}\right)\right)
\end{gathered}
$$

The $R F$ and $R$ models cannot be enabled at the same time. A condition for the transition between the $R F-R-R F$ partial models is given by (Ferreira, 1995)

$$
\begin{aligned}
& R F \rightarrow R \text { if } \mu_{s}^{r} \leq 0 \\
& R \rightarrow R F \text { if } \mu_{e}^{o} \leq 0
\end{aligned}
$$

\begin{tabular}{|c|c|c|c|}
\hline Parameter & Value & Parameter & Value \\
\hline$q_{s}^{\max }$ & $3.5 \mathrm{gS} / \mathrm{gX} \cdot \mathrm{h}$ & $k_{1}^{-1}$ & $0.49 g X / g S$ \\
\hline$q_{e}^{\max }$ & $0.236 g E / g X \cdot h$ & $k_{2}-1$ & $0.05 g X / g S$ \\
\hline$q_{0}^{\max }$ & $0.256 g_{2} / g X \cdot h$ & $k_{3}^{-1}$ & $0.1 \quad g X / g E$ \\
\hline$K_{i}$ & $0.1 \mathrm{~g} / \mathrm{l}$ & $k_{4}-1$ & $0.72 g X / g E$ \\
\hline$K_{o}$ & $0.0001 \mathrm{~g} / \mathrm{l}$ & $k_{5}-1$ & $1.2 \mathrm{gX} / \mathrm{gO}_{2}$ \\
\hline Csat & $7.0 \mathrm{mg} / \mathrm{l}$ & $k_{6}^{-1}$ & $0.64 \mathrm{gX} / \mathrm{gO}_{2}$ \\
\hline$S_{\text {in }}$ & $10 \mathrm{~g} / \mathrm{l}$ & $x_{1}(0)$ & $0.1 \mathrm{~g} / \mathrm{l}$ \\
\hline$K_{e}$ & $0.1 \mathrm{~g} / \mathrm{l}$ & $x_{2}(0)$ & $0.02 \mathrm{~g} / \mathrm{l}$ \\
\hline$K_{s}$ & $0.2 \mathrm{~g} / \mathrm{l}$ & $x_{3}(0)$ & $0.15 \mathrm{~g} / \mathrm{l}$ \\
\hline
\end{tabular}

The parameters values and the initial conditions for the $R F$ and $R$ partial models are given in table 2; a complete description of all parameters can be found in (Ferreira, 1995). The manipulated variable $u(t)=S_{\text {in }}$ was set as a square signal as can be seen in figure 4 . 


\begin{tabular}{c|l|c|c} 
Parameter & \multicolumn{1}{|c|}{ Value } & Parameter & Value \\
$K_{L} a$ & $100 \mathrm{1} / \mathrm{h}$ & $x_{4}(0)$ & $0.0066 \mathrm{mg} /$ \\
$D$ & $0.2 \mathrm{~h}$ & & \\
\hline
\end{tabular}

Table 2. Parameters values used in model (13)

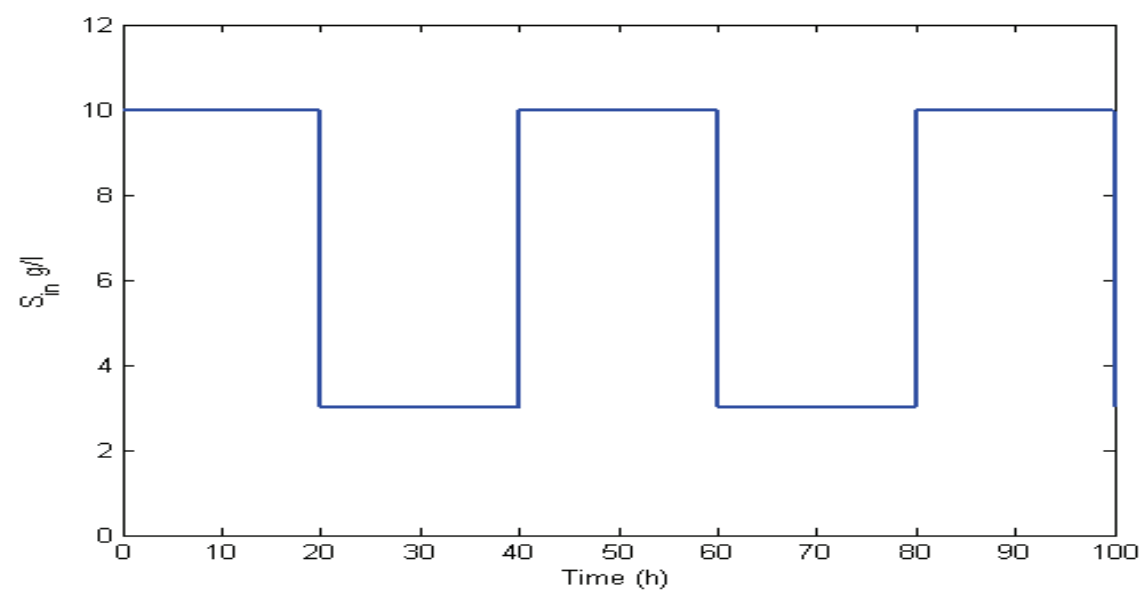

Fig. 4 Input square signal for the baker's yeast model

\section{The Takagi-Sugeno Fuzzy Exact Model}

When the nonlinear dynamic model for the baker's yeast is known, as well as all their parameters, a fuzzy exact model can be derived from the given nonlinear model. This requires a sector nonlinearity approach (Tanaka \& Wang, 2001).

\subsection{The Respiro-Fermentative Fuzzy Exact Model}

To construct the $R F$ exact fuzzy model we need to express the $R F$ partial model as a nonlinear system (16-17).

$$
\begin{gathered}
{\left[\begin{array}{c}
\dot{x}_{1} \\
\dot{x}_{2} \\
\dot{x}_{3} \\
\dot{x}_{4}
\end{array}\right]=\left[\begin{array}{cccc}
\mu_{s_{-} R F}^{o}+\mu_{s_{-} R F}^{r}-D & 0 & 0 & 0 \\
-k_{1} \mu_{s_{-} R F}^{o}-k_{2} \mu_{s_{-} R F}^{r} & -D & 0 & 0 \\
k_{3} \mu_{s_{-} R F}^{r} & 0 & -D & 0 \\
-k_{5} \mu_{s_{-} R F}^{o} & 0 & 0 & -D-K_{L} a
\end{array}\right]\left[\begin{array}{c}
x_{1} \\
x_{2} \\
x_{3} \\
x_{4}
\end{array}\right]+\left[\begin{array}{c}
0 \\
D \\
0 \\
0
\end{array}\right] S_{i n}+\left[\begin{array}{l}
0 \\
0 \\
0 \\
1
\end{array}\right] K_{L} a C^{\text {sat }}} \\
y(t)=h\left(x_{3}(t)\right)+h\left(x_{4}(t)\right)
\end{gathered}
$$

Substituting the specific rates (23) in the $f_{R F}(x(t))$ matrix from model (29), we obtain the matrix given by (31), for convenience called scheme $f_{R F_{-} I}$ 
scheme $f_{R F_{-} I}$

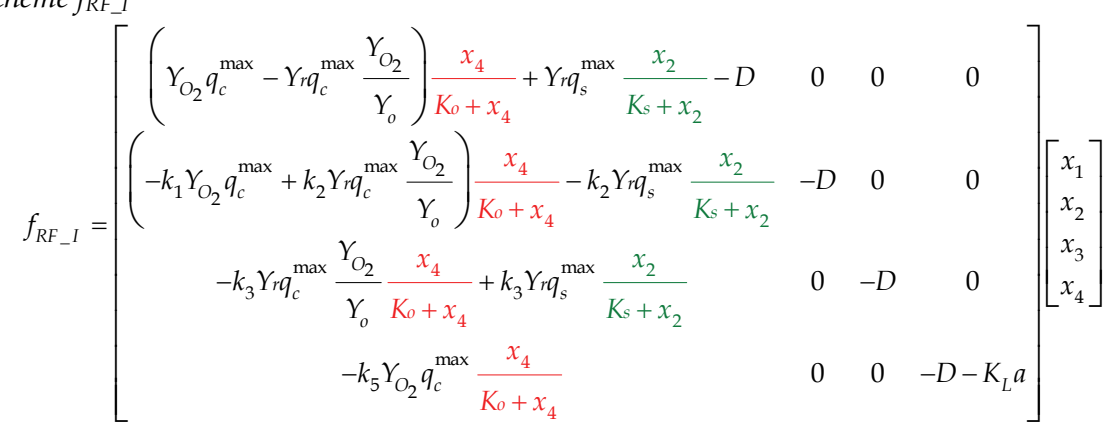

However; the matrix $f_{R F}(x(t))$ may also be written as:

Scheme $f_{R F_{-} I I}$

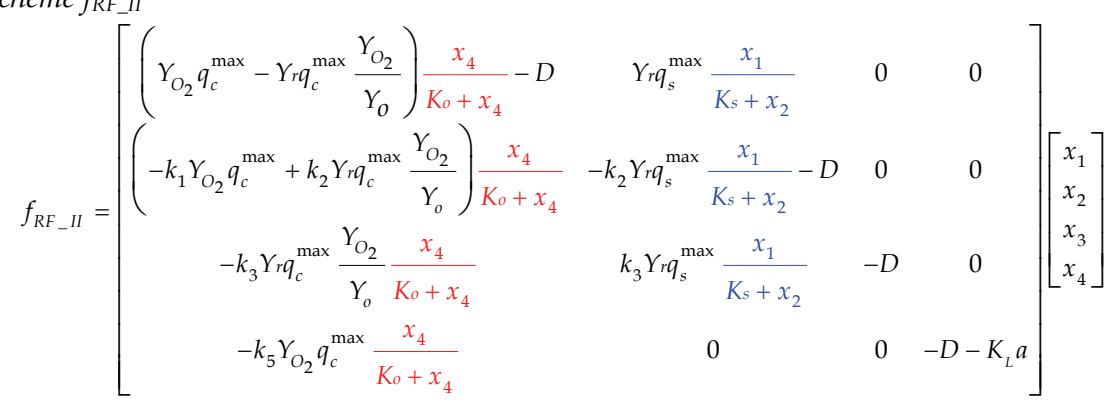

or as

Scheme $f_{\text {RF_III }}$

$$
f_{R F_{-} I I I}=\left[\begin{array}{ccccc}
Y_{O_{2}} q_{c}^{\max } \frac{x_{4}}{K_{0}+x_{4}}-D & Y_{r} q_{s}^{\max } \frac{x_{1}}{K_{s}+x_{2}} & 0 & -Y_{r} q_{c}^{\max } \frac{Y_{O_{2}}}{Y_{o}} \frac{x_{1}}{K_{o}+x_{4}} \\
-k_{1} Y_{O_{2}} q_{c}^{\max } \frac{x_{4}}{K_{0}+x_{4}} & -k_{2} Y_{r} q_{s}^{\max } \frac{x_{1}}{K_{s}+x_{2}}-D & 0 & k_{2} Y_{r} q_{c}^{\max } \frac{Y_{O_{2}}}{Y_{o}} \frac{x_{1}}{K_{o}+x_{4}} \\
0 & k_{3} Y_{r} q_{s}^{\max } \frac{x_{1}}{K_{s}+x_{2}} & -D & -k_{3} Y_{r} q_{c}^{\max } \frac{Y_{O_{2}}}{Y_{o}} \frac{x_{1}}{K_{o}+x_{4}} \\
-k_{5} Y_{O_{2}} q_{c}^{\max } \frac{x_{4}}{K_{0}+x_{4}} & 0 & 0 & -D-K_{L} a
\end{array}\right]\left[\begin{array}{c}
x_{1} \\
x_{2} \\
x_{3} \\
x_{4}
\end{array}\right]
$$

Although there are another possible combinations to write the $f_{R F}(x(t))$ matrix, with these approaches we obtain enough information to precise our point. From scheme $f_{R F_{-} I}$ (31) two nonlinearities can be detected 


$$
N L_{1}=\frac{x_{4}}{K_{0}+x_{4}} ; \quad N L_{2}=\frac{x_{2}}{K s+x_{2}}
$$

from scheme $f_{R F_{-} I}(32)$ also two different nonlinearities can be observed

$$
N L_{1}=\frac{x_{4}}{K_{0}+x_{4}} ; \quad N L_{3}=\frac{x_{1}}{K_{s}+x_{2}}
$$

and from scheme $f_{R F_{-} I I I}(33)$ three nonlinearities are present

$$
N L_{1}=\frac{x_{4}}{K_{0}+x_{4}} ; \quad N L_{3}=\frac{x_{1}}{K_{s}+x_{2}} ; \quad N L_{4}=\frac{x_{1}}{K_{0}+x_{4}}
$$

Although with each matrix given by (31-33) the exact fuzzy model can be built, it will take four linear subsystems $\left(2^{2}\right)$ for the scheme $f_{R F_{-} I}$ and scheme $f_{R F_{-} I I}$ and eight linear subsystems $\left(2^{3}\right)$ for scheme $f_{R F_{-} I I I}$. For convenience the nonlinearities (35) and the scheme $f_{R F_{-} I I}(32)$ are chosen to build the RF exact fuzzy model, the reason will be evident in the next section where the fuzzy observer is constructed. The premise variable $z_{1}^{R F}(t)$ is defined as

$$
N L_{1}=z_{1}^{R F}(t)=\frac{x_{4}}{K_{0}+x_{4}} ; \quad \text { for } x_{4} \neq-K_{o}
$$

From equation (37) the maximum and minimum values of $z_{1}^{R F}(t)$ can be obtained. In figure 5 the plot of (37) can be observed.

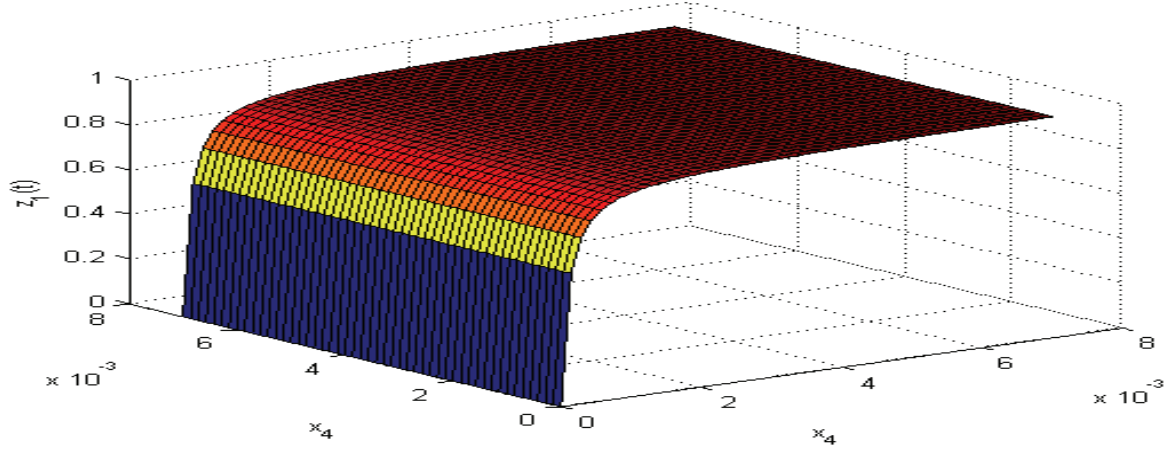

Fig. 5 Plot for the premise variable $z_{1}^{R F}(t)$ 
The maximum and minimum values of $z_{1}^{R F}(t)$ in the range $x_{4}(t) \in[0,0.007]$ are given by

$$
\max _{x_{4}(t)} z_{1}(t)=0.9859=a_{1} \quad \min _{x_{4}(t)} z_{1}(t)=0=a_{2}
$$

we define the premise variable $z_{2}^{R F}(t)$ as:

$$
N L_{3}=z_{2}^{R F}(t)=\frac{x_{1}}{K_{s}+x_{2}} ; \quad \text { for } x_{2} \neq-K s
$$

From equation (39) the maximum and minimum values of $z_{2}^{R F}(t)$ can be obtained, as shown in figure 6,

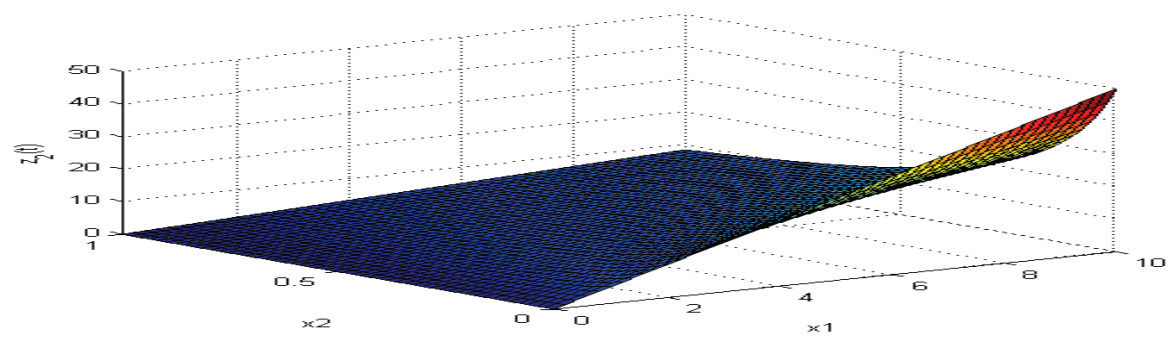

Fig. 6 Plot for the premise variable $z_{2}^{R F}(t)$

The maximum and minimum values of $z_{2}^{R F}(t)$ in the range $x_{1}(t) \in[0,10]$ and $x_{2}(t) \in[0,1]$ are given by

$$
\max _{x_{1}(t) x_{2}(t)} z_{2}(t)=50=b_{1} \quad \min _{x_{1}(t) x_{2}(t)} z_{2}(t)=0=b_{2}
$$

The membership functions are built from these equations

$$
\begin{aligned}
& z_{1}^{R F}(t)=\sum_{i=1}^{2} \varphi_{1 i}\left(z_{1}^{R F}(t)\right) a_{i} \\
& z_{2}^{R F}(t)=\sum_{j=1}^{2} \varphi_{2 j}\left(z_{2}^{R F}(t)\right) b_{j}
\end{aligned}
$$

where the following properties must hold 


$$
\begin{gathered}
\varphi_{11}\left(z_{1}^{R F}(t)\right)+\varphi_{12}\left(z_{1}^{R F}(t)\right)=1 \\
\varphi_{21}\left(z_{2}^{R F}(t)\right)+\varphi_{22}\left(z_{2}^{R F}(t)\right)=1
\end{gathered}
$$

Solving equations (41 and 42) the following membership functions are obtained

$$
\begin{array}{ll}
\varphi_{11}\left(z_{1}(t)\right)=\frac{z_{1}(t)-a_{2}}{a_{1}-a_{2}} & \varphi_{12}\left(z_{1}(t)\right)=\frac{-z_{1}(t)+a_{1}}{a_{1}-a_{2}} \\
\varphi_{21}\left(z_{2}(t)\right)=\frac{z_{2}(t)-b_{2}}{b_{1}-b_{2}} & \varphi_{22}\left(z_{2}(t)\right)=\frac{-z_{2}(t)+b_{1}}{b_{1}-b_{2}}
\end{array}
$$

Substituting the maximum and minimum values $a_{1}, a_{2}, b_{1}$ and $b_{2}$ in (32) we obtain 4 possible combinations to express the linear subsystems.

$$
A_{i j}^{R F}=\left[\begin{array}{cccc}
\left(Y_{O_{2}} q_{c}^{\max }-Y_{r} q_{c}^{\max } \frac{Y_{O_{2}}}{Y_{o}}\right) a_{i}-D & Y_{r} q_{s}^{\max } b_{j} & 0 & 0 \\
\left(-k_{1} Y_{O_{2}} q_{c}^{\max }+k_{2} Y_{r} q_{c}^{\max } \frac{Y_{O_{2}}}{Y_{o}}\right) a_{i} & -k_{2} Y_{r} q_{s}^{\max } b_{j}-D & 0 & 0 \\
-k_{3} Y_{r} q_{c}^{\max } \frac{Y_{O_{2}}}{Y_{o}} a_{i} & k_{3} Y_{r} q_{s}^{\max } b_{j} & -D & 0 \\
-k_{5} Y_{O_{2}} q_{c}^{\max } a_{i} & 0 & 0 & -D-K_{L} a
\end{array}\right]\left[\begin{array}{l}
x_{1} \\
x_{2} \\
x_{3} \\
x_{4}
\end{array}\right]
$$

$$
i, j=1,2
$$

The fuzzy rules for the $R F$ partial model are stated as:

$$
\begin{aligned}
& \text { If } z_{1}(t) \text { is " } \varphi_{11}\left(z_{1}(t)\right) \text { " and } z_{2}(t) \text { is " } \varphi_{21}\left(z_{2}(t)\right) \text { " } \\
& \text { THEN } \dot{x}_{11}^{R F}(t)=A_{11}^{R F} x(t)+B u(t)+d \\
& \text { If } z_{1}(t) \text { is " } \varphi_{11}\left(z_{1}(t)\right) \text { " and } z_{2}(t) \text { is " } \varphi_{22}\left(z_{2}(t)\right) \text { " } \\
& \text { THEN } \dot{x}_{12}^{R F}(t)=A_{12}^{R F} x(t)+B u(t)+d \\
& \text { If } z_{1}(t) \text { is " } \varphi_{12}\left(z_{1}(t)\right) \text { " and } z_{2}(t) \text { is " } \varphi_{21}\left(z_{2}(t)\right) \text { " } \\
& \text { THEN } \dot{x}_{21}^{R F}(t)=A_{21}^{R F} x(t)+B u(t)+d \\
& \text { If } z_{1}(t) \text { is " } \varphi_{12}\left(z_{1}(t)\right) \text { " and } z_{2}(t) \text { is " } \varphi_{22}\left(z_{2}(t)\right) \text { " } \\
& \text { THEN } \dot{x}_{22}^{R F}(t)=A_{22}^{R F} x(t)+B u(t)+d
\end{aligned}
$$


The aggregated model for the RF partial model is given by

$$
\begin{aligned}
& \dot{x}^{R F}(t)=\sum_{i=1}^{2} \sum_{j=1}^{2} \varphi_{1 i}\left(z_{1}(t)\right) \varphi_{2 j}\left(z_{2}(t)\right)\left\{A_{i j}^{R F} x(t)+B u(t)+d\right\} \\
& y^{R F}(t)=\sum_{i=1}^{2} \sum_{j=1}^{2} \varphi_{1 i}\left(z_{1}(t)\right) \varphi_{2 j}\left(z_{2}(t)\right) C x(t), \quad i, j=1,2 .
\end{aligned}
$$

\subsection{The Respirative Fuzzy Exact Model}

The $R$ partial exact model can also be built following the procedure described in section 4.1. We must be aware that the $R$ model must be split in two models called $R_{q e 1}$ and $R_{q e 2}$. As in schemes (31-33) several possibilities may be formulated to build the R model, therefore a possibility to express the $f_{R}(x(t))$ matrix $\left(f_{R q e 1}\right.$ and $\left.f_{R q e 2}\right)$ can be written as:

Scheme $f_{\text {Rqe1_I }}$

$$
f_{\text {Rqe } 1}=\left[\begin{array}{cccc}
Y_{e} q_{e}^{\max } K i \frac{x_{3}}{\left(K_{e}+x_{3}\right)\left(K_{i}+x_{2}\right)}-D & Y_{o} q_{s}^{\max } \frac{x_{1}}{K_{s}+x_{2}} & 0 & 0 \\
0 & -k_{1} Y_{o} q_{s}^{\max } \frac{x_{1}}{K_{s}+x_{2}}-D & 0 & 0 \\
-k_{4} Y_{e} q_{e}^{\max } K_{i} \frac{x_{3}}{\left(K_{e}+x_{3}\right)\left(K_{i}+x_{2}\right)} & 0 & -D & 0 \\
-k_{6} Y_{e} q_{e}^{\max } K i \frac{x_{3}}{\left(K_{e}+x_{3}\right)\left(K_{i}+x_{2}\right)} & -k_{5} Y_{o} q_{s}^{\max \frac{x_{1}}{K_{s}+x_{2}}} & 0 & -D-K_{L} a
\end{array}\right]\left[\begin{array}{c}
x_{1} \\
x_{2} \\
x_{3} \\
x_{4}
\end{array}\right]
$$

Scheme $f_{\text {Rqe2_I }}$

$$
f_{R q e 2}=\left[\begin{array}{cccc}
Y_{O_{2}}{ }^{e q} q_{c}^{\max } \frac{x_{4}}{K_{0}+x_{4}}-D & \left(Y_{o} q_{s}^{\max }-Y_{O_{2}} e q_{s}^{\max } \frac{Y_{o}}{Y_{O_{2}}}\right) \frac{x_{1}}{K_{s}+x_{2}} & 0 & 0 \\
0 & -k_{1} Y_{o} q_{s}^{\max } \frac{x_{1}}{K_{s}+x_{2}}-D & 0 & 0 \\
-k_{4} Y_{O_{2}} e q_{c}^{\max } \frac{x_{4}}{K_{o}+x_{4}} & k_{4} Y_{O_{2}} e q_{s}^{\max } \frac{Y_{o}}{Y_{O_{2}}} \frac{x_{1}}{K_{s}+x_{2}} & -D & 0 \\
-k_{6} Y_{O_{2} e} q_{c}^{\max } \frac{x_{4}}{K_{o}+x_{4}} & \left(-k_{5} Y_{o} q_{s}^{\max }+k_{6} Y_{O_{2}} e q_{s}^{\max } \frac{Y_{o}}{Y_{O_{2}}}\right) \frac{x_{1}}{K_{s}+x_{2}} & 0 & -D-K_{L} a
\end{array}\right]\left[\begin{array}{c}
x_{1} \\
x_{2} \\
x_{3} \\
x_{4}
\end{array}\right]
$$

To construct the exact model for the $R$ partial model we must use the nonlinearities from models (46-47). For model 46 we have that the first nonlinearity is given by

$$
N L_{5}=z_{3}^{R q e 1}(t)=\frac{x_{3}}{\left(K_{e}+x_{3}\right)\left(K_{i}+x_{2}\right)} ; \quad \text { for } x_{3} \neq-K_{e} \text { and } x_{2} \neq-K_{i}
$$


where the maximum and minimum values are given by

$$
\max _{x_{2}(t) x_{3}(t)} z_{3}(t)=9.8039=c_{1} \quad \min _{x_{2}(t) x_{3}(t)} z_{3}(t)=0.1=c_{2}
$$

The remaining nonlinearities from models (46) and (47) were the same already described by (37) and (39). The linear subsystems for the $R_{q e 1}$ model can be obtained from

$$
\begin{aligned}
A_{R_{q e 1}} & =\left[\begin{array}{cccc}
Y_{e} q_{e}^{\max } K i c_{k}-D & Y_{o} q_{s}^{\max } b_{j} & 0 & 0 \\
0 & -k_{1} Y_{o} q_{s}^{\max } b_{j}-D & 0 & 0 \\
-k_{4} Y_{e} q_{e}^{\max } K i c_{k} & 0 & -D & 0 \\
-k_{6} Y_{e} q_{e}^{\max } K i c_{k} & -k_{5} Y_{o} q_{s}^{\max } b_{j} & 0 & -D
\end{array}\right] \\
& j k=1,2
\end{aligned}
$$

and

$$
A_{R_{q e 2}}=\left[\begin{array}{cccc}
Y_{O_{2}} e q_{c}^{\max } a i-D & \left(Y_{o} q_{s}^{\max }-Y_{O_{2}} e q_{s}^{\max } \frac{Y_{o}}{Y_{O_{2}}}\right) b_{j} & 0 & 0 \\
0 & -k_{1} Y_{o} q_{s}^{\max } b_{j}-D & 0 & 0 \\
-k_{4} Y_{O_{2}} e q_{c}^{\max } a i & k_{4} Y_{O_{2}}{ }^{e} q_{s}^{\max } \frac{Y_{o}}{Y_{O_{2}}} b_{j} & -D & 0 \\
-k_{6} Y_{O_{2}} e q_{c}^{\max } a i & \left(-k_{5} Y_{o} q_{s}^{\max }+k_{6} Y_{O_{2}} e q_{s}^{\max } \frac{Y_{o}}{Y_{O_{2}}}\right) b_{j} & 0 & -D
\end{array}\right]
$$

A general model to obtain the rules for the $R_{q e 1}$ and $R_{q e 2}$ partial models is expressed as for $R_{q e 1}$

$$
\begin{aligned}
& \text { If } \left.\left.z_{1}(t) \text { is " } \varphi_{1 i}\left(z_{1}(t)\right) \text { " and } z_{3}(t) \text { is " } \varphi_{3 k}\left(z_{3}(t)\right) "\right)\right) " \\
& \text { THEN } \dot{x}^{\text {Rqe } 1}(t)=A_{j k}^{R q e 1} x(t)+B u(t)+d ; \quad j k=1,2
\end{aligned}
$$

and for $R_{q e 2}$

$$
\begin{aligned}
& \text { If } z_{1}(t) \text { is " } \varphi_{1 i}\left(z_{1}(t)\right) \text { " and } z_{2}(t) \text { is " } \varphi_{2 j}\left(z_{2}(t)\right) \text { " } \\
& \text { THEN } \dot{x}^{\text {Rqe } 2}(t)=A_{i j}^{\text {Rqe } 2} x(t)+B u(t)+d ; \quad i j=1,2
\end{aligned}
$$

Finally the aggregated model for the $R_{q e 1}$ and $R_{q e 2}$ partial models is expressed as: for $R_{\text {qe1 }}$ 


$$
\begin{aligned}
& \dot{x}^{\text {Rqe } 1}(t)=\sum_{j=1}^{2} \sum_{k=1}^{2} \varphi_{1 j}\left(z_{1}(t)\right) \varphi_{3 k}\left(z_{3}(t)\right)\left\{A_{j k}^{R q e 1} x(t)+B u(t)+d\right\} \\
& y^{R q e 1}(t)=\sum_{j=1}^{2} \sum_{k=1}^{2} \varphi_{1 j}\left(z_{1}(t)\right) \varphi_{3 k}\left(z_{3}(t)\right) C x(t), \quad \quad \mathrm{j}, k=1,2 .
\end{aligned}
$$

and for $R_{q e 2}$

$$
\begin{aligned}
& \dot{x}^{\text {Rqe } 2}(t)=\sum_{i=1}^{2} \sum_{j=1}^{2} \varphi_{1 i}\left(z_{1}(t)\right) \varphi_{2 j}\left(z_{2}(t)\right)\left\{A_{i j}^{\text {Rqe } 2} x(t)+B u(t)+d\right\} \\
& y^{\text {Rqe } 2}(t)=\sum_{i=1}^{2} \sum_{j=1}^{2} \varphi_{1 i}\left(z_{1}(t)\right) \varphi_{2 j}\left(z_{2}(t)\right) C x(t), \quad i, j=1,2 .
\end{aligned}
$$

Although the premise variables for the partial models $R F$ and $R_{q e 2}$ were the same (37) and (39), they have different behaviors as they are multiplied by different yield coefficients. The aggregated models (45) and (52-53) represents exactly the nonlinear system (13) in the region

$$
x_{1}(t) \in[0,10], x_{2}(t) \in[0,1], x_{3}(t) \in[0,5] \text { and } x_{4}(t) \in[0,0.007]
$$

A condition for the transition between the $R F-R-R F$ partial models is given by (28).

\section{Fuzzy Observer}

Now that an exact fuzzy model for the nonlinear baker's yeast partial model has been obtained, a fuzzy observer can now be designed. First of all we have to test the observability matrix for the obtained linear subsystems. A linear system is said to be observable if for any unknown initial state $x(0)$ there exist a finite $t_{1}>0$ such as the knowledge of the input $u$ and the output $y$ over $\left[0, t_{1}\right]$ suffices to determine uniquely the initial state $x(0)$. Otherwise the equation is unobservable (Chen, 1999). The pair $(A, C)$ is observable if and only if the observability matrix

$$
O=\left[\begin{array}{ccc}
C & C A^{2}, \ldots, C A^{n-1}
\end{array}\right]^{\mathrm{T}}=n,
$$

\begin{tabular}{|c|c|}
\hline Schemes & observability rank for $C=\left[\begin{array}{llll}0 & 0 & 1 & 1\end{array}\right]$ \\
\hline$\overline{f_{R F_{-} I}}$ & $\begin{array}{llll}3 & 3 & 3 & 3\end{array}$ \\
\hline$f_{R F_{-} I I}$ & 44 \\
\hline$f_{\text {RF_III }}$ & $\begin{array}{llllllll}4 & 4 & 4 & 4 & 4 & 3 & 4 & 3\end{array}$ \\
\hline
\end{tabular}

has full rank $(\rho(O)=n)$ i.e. is nonsingular.

In section 4.1 we remark that the fuzzy exact model for the $R F$ model may be built from three schemes (among many others) namely $f_{R F_{-} I}$ (31), $f_{R F_{-} I I}$ (32) and $f_{R F_{-} I I I}$ (33). If we build the fuzzy exact model for each scheme (31-33) and we test the observability matrix for these linear subsystems; for example (44), we should find that (table 3)

Table 3. Observability matrix for schemes (31-33) 
From table 3 we may notice that no full rank is achieved for $f_{R F_{-}}$, therefore a full observer cannot be built for this scheme. For schemes $f_{R F_{-} I I}$ and $f_{R F_{-} I I I}$ almost full rank is achieved in every linear subsystem; however, for scheme $f_{R F_{-} I I I}$ it will take eight linear subsystems to build the fuzzy exact model, while for scheme $f_{R F_{-} I}$ only four linear subsystems will be needed. To avoid build complicated linear systems, scheme $f_{R F_{-} I I}$ was chosen to construct the Exact fuzzy observer. Therefore before constructing a fuzzy exact model for an observer or a controller, it will be advisable to analyze the way the premise variables are chosen to avoid lack of observability or controllability.

The following assumptions were made to build the fuzzy observer:

H1. The nominal values of the yield coefficients $k_{1,}-k_{6}$ are constant and known.

$\mathrm{H} 2$. The ethanol, the dissolved oxygen concentration and the OTR are known.

The procedure to build the exact fuzzy observer is the same that was followed for the fuzzy exact model, although some considerations must be taken into account. An important consideration is related with the scheme (32) where the premise variable (39) will depend on the estimated state $x_{1}$ and $x_{2}$, therefore the premise variable must be modified to:

$$
\hat{z}_{2}^{R F}(t)=\frac{\hat{x}_{1}}{K_{s}+\hat{x}_{2}} ; \quad \text { for } \hat{x}_{2} \neq-K s
$$

The same situation applies to the premise variable of model (46)

$$
z_{3}^{\text {Rqe } 1}(t)=\frac{x_{3}}{\left(K_{e}+x_{3}\right)\left(K_{i}+\hat{x}_{2}\right)} ; \quad \text { for } x_{3} \neq-K_{e} \text { and } \hat{x}_{2} \neq-K_{i}
$$

The premise variable (37) remains unchanged. To guarantee full observability rank (table 4) the minimum values of the premise variables are modified to

$$
\min _{x_{4}(t)} z_{1}(t)=a_{2}=\min _{x_{1}(t) x_{2}(t)} z_{2}(t)=b_{2}=\min _{x_{2}(t) x_{3}(t)} z_{3}(t)=c_{2}=0.1
$$

\begin{tabular}{c|rrrr}
\hline Schemes & Linear subsystems observability rank \\
\hline$f_{\text {RF_II }}$ & 4 & 4 & 4 & 4 \\
$f_{\text {Rqe1_I }}$ & 4 & 4 & 4 & 4 \\
$f_{\text {Rqe2_I }}$ & 4 & 4 & 4 & 4 \\
\hline
\end{tabular}

Table 4 Observability matrix for the linear subsystems $(44,50-51)$

The membership functions are built as before; nevertheless, for (54-55) we have 


$$
\begin{array}{ll}
\varphi_{21}\left(\hat{z}_{2}(t)\right)=\frac{\hat{z}_{2}(t)-b_{2}}{b_{1}-b_{2}} & \varphi_{22}\left(\hat{z}_{2}(t)\right)=\frac{-\hat{z}_{2}(t)+b_{1}}{b_{1}-b_{2}} \\
\varphi_{31}\left(\hat{z}_{3}(t)\right)=\frac{\hat{z}_{3}(t)-c_{2}}{c_{1}-c_{2}} & \varphi_{32}\left(\hat{z}_{3}(t)\right)=\frac{-\hat{z}_{3}(t)+c_{1}}{c_{1}-c_{2}}
\end{array}
$$

The linear subsystems given by (44), (50-51) are used to built the fuzzy observer. A general rule to obtain all the fuzzy rules for the $R F, R_{q e 1}$ and $R_{q e 2}$ partial models are given by:

for $R F$

$$
\begin{aligned}
& \text { If } \hat{z}_{1}(t) \text { is " } \varphi_{1 i}\left(z_{1}(t)\right) \text { " and } z_{2}(t) \text { is " } \varphi_{2 j}\left(z_{2}(t)\right) \text { " } \\
& \text { THEN } \hat{\dot{x}}^{R F}(t)=A_{i j}^{R F} \hat{x}(t)+B u(t)+K_{i j}^{R F}(y(t)-\hat{y}(t))+K_{L} a C^{s a t} ; j=1,2
\end{aligned}
$$

for $R_{q e 1}$

If $\hat{z}_{1}(t)$ is " $\varphi_{1 j}\left(z_{1}(t)\right)$ " and $\hat{z}_{3}(t)$ is " $\varphi_{3 k}\left(z_{3}(t)\right)$ "

$$
\operatorname{THEN} \hat{\dot{x}}^{R q e 1}(t)=A_{j k}^{R q e 1} \hat{x}(t)+B u(t)+K_{j k}^{R q e 1}(y(t)-\hat{y}(t))+K_{L} a C^{\text {sat }} ; j k=1,2
$$

for $R_{q e 2}$

$$
\begin{aligned}
& \text { If } \hat{z}_{1}(t) \text { is " } \varphi_{1 i}\left(z_{1}(t)\right) \text { " and } z_{2}(t) \text { is " } \varphi_{2 j}\left(z_{2}(t)\right) \text { " } \\
& \text { THEN } \hat{\dot{x}}^{\text {Rqe } 2}(t)=A_{i j}^{R q e 2} \hat{x}(t)+B u(t)+K_{i j}^{R q e 2}(y(t)-\hat{y}(t))+K_{L} a C^{\text {sat }} ; \quad i j=1,2
\end{aligned}
$$

The aggregated fuzzy observers for the $R F, R_{q e 1}$ and $R_{q e 2}$ partial models are given by for $R F$

$$
\begin{array}{lc}
\hat{\dot{x}}^{R F}(t)=\sum_{i=1}^{2} \sum_{j=1}^{2} \varphi_{1 i}\left(\hat{z}_{1}(t)\right) \varphi_{2 j}\left(z_{2}(t)\right)\left\{A_{i j}^{R F} \hat{x}(t)+B u(t)+K_{i j}^{R F}(y(t)-\hat{y}(t))+K_{L} a C^{s a t}\right\} \\
\hat{y}^{R F}(t)=\sum_{i=1}^{2} \sum_{j=1}^{2} \varphi_{1 i}\left(\hat{z}_{1}(t)\right) \varphi_{2 j}\left(z_{2}(t)\right) C \hat{x}(t), & i, j=1,2 .
\end{array}
$$

for $R_{q e 1}$

$$
\begin{aligned}
& \hat{\dot{x}}^{R q e 1}(t)=\sum_{j=1}^{2} \sum_{k=1}^{2} \varphi_{1 j}\left(\hat{z}_{1}(t)\right) \varphi_{3 k}\left(\hat{z}_{3}(t)\right)\left\{A_{j k}^{R q e 1} \hat{x}(t)+B u(t)+K_{j k}^{R q e 1}(y(t)-\hat{y}(t))+K_{L} a C^{s a t}\right\} \\
& \hat{y}^{R g e 1}(t)=\sum_{j=1}^{2} \sum_{k=1}^{2} \varphi_{1 j}\left(\hat{z}_{1}(t)\right) \varphi_{3 k}\left(\hat{z}_{3}(t)\right) C \hat{x}(t), \quad j, k=1,2 .
\end{aligned}
$$

for $R_{q e 2}$ 


$$
\begin{array}{cc}
\hat{\dot{x}}^{\text {Rqe } 2}(t)=\sum_{i=1}^{2} \sum_{j=1}^{2} \varphi_{1 i}\left(\hat{z}_{1}(t)\right) \varphi_{2 j}\left(z_{2}(t)\right)\left\{A_{i j}^{\text {Rqe } 2} \hat{x}(t)+B u(t)+K_{i j}^{R g e 2}(y(t)-\hat{y}(t))+K_{L} a C^{\text {sat }}\right\} \\
\hat{y}^{\text {Rqe } 2}(t)=\sum_{i=1}^{2} \sum_{j=1}^{2} \varphi_{1 i}\left(\hat{z}_{1}(t)\right) \varphi_{2 j}\left(z_{2}(t)\right) C \hat{x}(t), & i, j=1,2 .
\end{array}
$$

\subsection{Fuzzy Observer Simulation}

The application of the proposed observer scheme was simulated using MATLABTM. The fuzzy observers were tested using the continuous $R F$ and the $R$ baker's yeast partial models given above. The inlet substrate concentration was varied between $3 \mathrm{~g} / 1$ and $10 \mathrm{~g} / \mathrm{l}$ in order to force the switching between the partial models. The partial models parameters were given in table 2 . The decay rate $(\alpha)$ was set to zero. The estimated variables were the biomass and the substrate, each observed variable was tested with three different initial conditions 1, 3 and $4 \mathrm{~g} / 1$ for biomass, and $0.01,0.03$ and $0.06 \mathrm{~g} / 1$ for substrate. The behavior of the fuzzy observer for biomass estimation is shown in figure 7 . The observer converges around the 20 hours of fermentation elapsed time, almost in the $R_{q e 2}$ partial model. It can be noticed the dynamics of the baker's yeast switching through the $R F, R_{q e 1}$ and $R_{q e 2}$ partial models. The observer substrate converges around the 15 hours of fermentation elapsed time (figure 8), therefore the substrate dynamics is faster than the biomass. The observer gains are displayed in table 5 and were calculated from the inequalities (8) through Linear Matrix Inequalities.

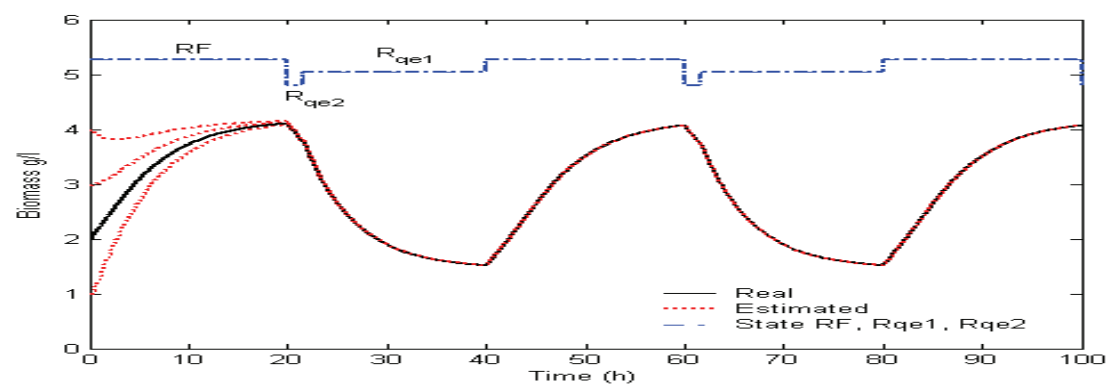

Fig. 7 Biomass observer performance with $\alpha=0$ and $\hat{x}_{1}(0)=1,3$ and $4 \mathrm{~g} / 1$.

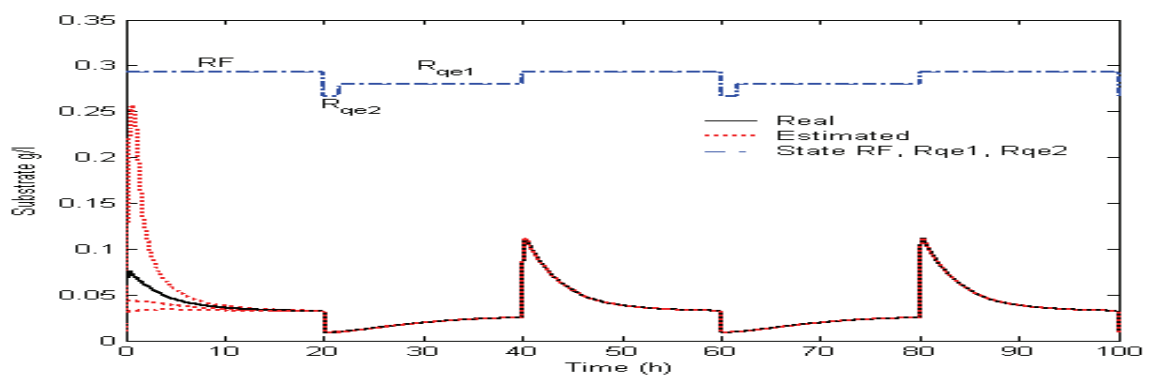

Fig. 8 Substrate observer performance with $\alpha=0$ and $\hat{x}_{2}(0)=0.01,0.03$ and $0.06 \mathrm{~g} / 1$. 


\begin{tabular}{c|c|c|c|c}
\hline Gain & $x_{1}$ & $x_{2}$ & $x_{3}$ & $x_{4}$ \\
\hline $\mathrm{K}_{1 \_ \text {RF }}$ & -1309.8 & 2019.2 & 409.79 & -498.19 \\
$\mathrm{~K}_{2}$ RF & -707.7 & -1299.2 & 1553.5 & -1611.5 \\
$\mathrm{~K}_{3}$ RF & -1304.4 & 2015.3 & 405.83 & -494.33 \\
$\mathrm{~K}_{4 \_ \text {RF }}$ & -702.28 & -1303.1 & 1549.6 & -1607.6 \\
$\mathrm{~K}_{1 \_ \text {Rqe1 }}$ & 1937.1 & -4136.6 & 113.86 & -213.31 \\
$\mathrm{~K}_{2}$ Rqe1 & 1945.6 & -4153.3 & 113.56 & -213.03 \\
$\mathrm{~K}_{3}$ Rqe1 & -58.432 & -11.52 & 94.846 & -192.06 \\
$\mathrm{~K}_{4}$ Rqe1 & -49.883 & -28.246 & 94.539 & -191.77 \\
$\mathrm{~K}_{1 \_ \text {Rqe2 }}$ & -845.59 & 1626.8 & 109 & -205.81 \\
$\mathrm{~K}_{2}$ Rqe2 & -12.963 & -1569.3 & 1112.7 & -1185.8 \\
$\mathrm{~K}_{3}$ Rqe2 & -842.39 & 1620.4 & 108.95 & -205.76 \\
$\mathrm{~K}_{4 \_ \text {Rqe2 }}$ & -9.761 & -1575.6 & 1112.7 & -1185.8 \\
\hline
\end{tabular}

Table 5. Observer gains, with $a=0$.

Common positive definite matrices that guarantees global asymptotic stability (Tanaka \& Wang, 2001), were found for each partial model, namely

$$
\begin{gathered}
P_{R F}=\left[\begin{array}{cccc}
2.4375 \times 10^{-4} & -1.7425 \times 10^{-4} & -1.7842 \times 10^{-4} & 1.7363 \times 10^{-4} \\
-1.7425 \times 10^{-4} & 9.6041 \times 10^{-4} & -3.3103 \times 10^{-4} & 3.2221 \times 10^{-4} \\
-1.7842 \times 10^{-4} & -3.3103 \times 10^{-4} & 3.9367 \times 10^{-4} & -3.8324 \times 10^{-4} \\
1.7363 \times 10^{-4} & 3.2221 \times 10^{-4} & -3.8324 \times 10^{-4} & 3.9792 \times 10^{-4}
\end{array}\right], \\
P_{\text {Rqe1 }}=\left[\begin{array}{llll}
5.7188 \times 10^{-5} & -1.1189 \times 10^{-4} & -2.0528 \times 10^{-6} & 1.9285 \times 10^{-6} \\
-1.1189 \times 10^{-4} & 2.313 \times 10^{-4} & -1.0663 \times 10^{-6} & 1.192 \times 10^{-6} \\
-2.0528 \times 10^{-6} & -1.0663 \times 10^{-6} & 3.8217 \times 10^{-6} & -3.7426 \times 10^{-6} \\
1.9285 \times 10^{-6} & 1.192 \times 10^{-6} & -3.7426 \times 10^{-6} & 7.6266 \times 10^{-6}
\end{array}\right], \\
P_{\text {Rqe2 }}=\left[\begin{array}{llll}
1.0333 \times 10^{-4} & -2.0491 \times 10^{-4} & -1.5395 \times 10^{-6} & 1.4853 \times 10^{-6} \\
-2.0491 \times 10^{-4} & 7.8655 \times 10^{-4} & -2.4702 \times 10^{-4} & 2.4119 \times 10^{-4} \\
-1.5395 \times 10^{-6} & -2.4702 \times 10^{-4} & 1.7446 \times 10^{-4} & -1.7037 \times 10^{-4} \\
1.4853 \times 10^{-6} & 2.4119 \times 10^{-4} & -1.7037 \times 10^{-4} & 1.8174 \times 10^{-4}
\end{array}\right]
\end{gathered}
$$

To improve the observer performance the decay rate ratio $(\alpha)$ was set to 0.3 . The behavior of the fuzzy observer for biomass estimation is shown in figure 9. The observer converges in about 6 hours of fermentation elapsed time, now within the RF state. The observer substrate converges around the 5 hours of fermentation elapsed time (figure 10). The observer gains for $\alpha=0.3$ are displayed in table 6 and were calculated using the inequalities given by (8). 


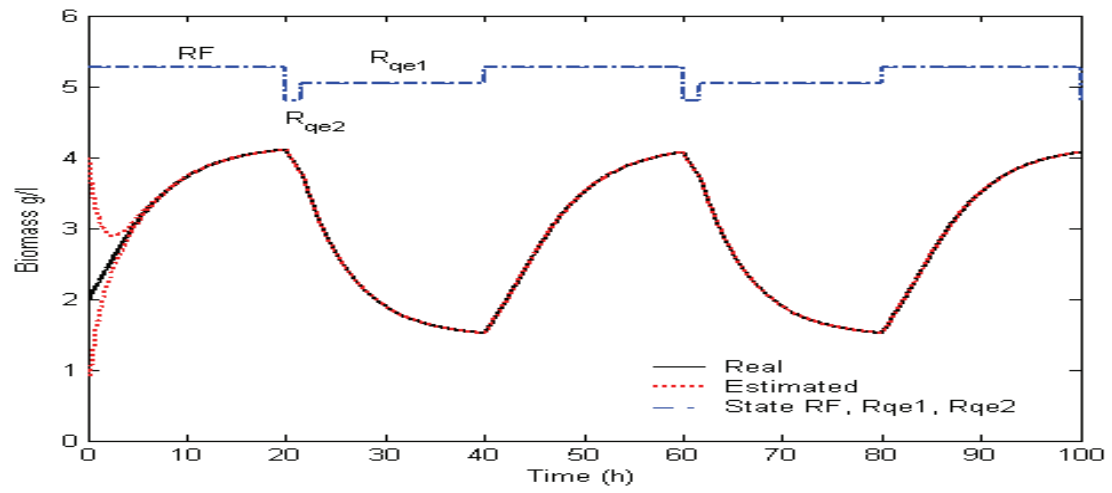

Fig. 9 Biomass observer performance with $\alpha=0.3$ and $\hat{x}_{1}(0)=1,3$ and $4 \mathrm{~g} / \mathrm{l}$.

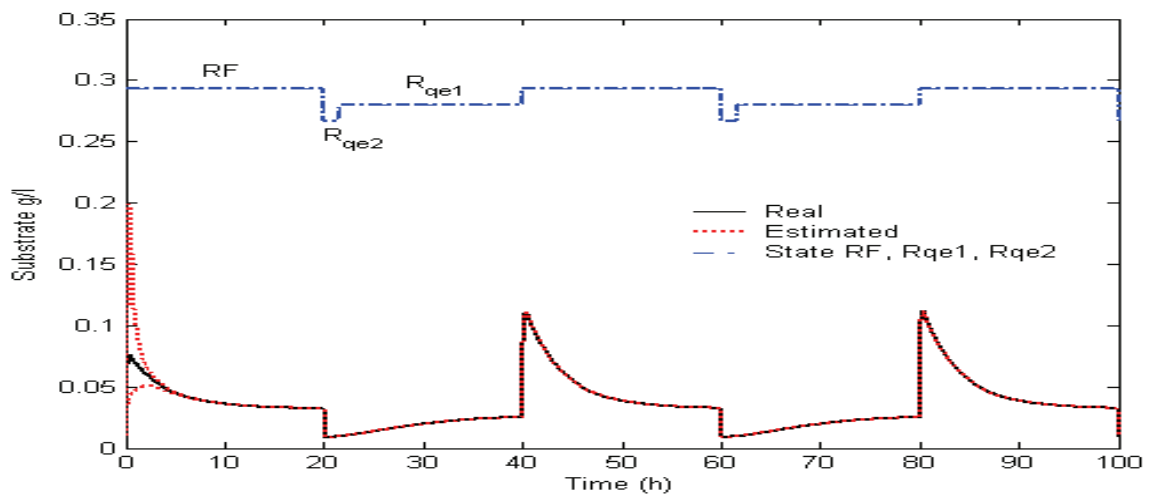

Fig. 10 Substrate observer performance with $\alpha=0$ and $\hat{x}_{2}(0)=0.01,0.03$ and $0.06 \mathrm{~g} / 1$.

\begin{tabular}{c|c|c|c|c}
\hline Gain & $x_{1}$ & $x_{2}$ & $x_{3}$ & $x_{4}$ \\
\hline $\mathrm{K}_{1 \_ \text {RF }}$ & -45325 & 10803 & 1898.6 & -1944.6 \\
$\mathrm{~K}_{2}$ RF & -15713 & -270.57 & 2674.9 & -2707.9 \\
$\mathrm{~K}_{3 \_ \text {RF }}$ & -43990 & 10667 & 1784.5 & -1833.4 \\
$\mathrm{~K}_{4}$ RF & -14378 & -406.29 & 2560.8 & -2596.7 \\
$\mathrm{~K}_{1 \_ \text {Rqe1 }}$ & -84248 & -5319.8 & 1619.2 & -1647.6 \\
$\mathrm{~K}_{2}$ Rqe1 & -66998 & -5161.4 & 1320.5 & -1362.6 \\
$\mathrm{~K}_{3 \_ \text {Rqe1 }}$ & -65489 & -714.01 & 1220 & -1262.5 \\
$\mathrm{~K}_{4}$ _Rqe1 & -48239 & -555.65 & 921.3 & -977.46 \\
$\mathrm{~K}_{1 \_ \text {Rqe2 }}$ & -41344 & 5226.6 & 3786.8 & -3783.1 \\
$\mathrm{~K}_{2}$ Rqe2 & -24341 & 1700.4 & 2765.6 & -2790.6 \\
$\mathrm{~K}_{3-\text { Rqe2 }}$ & -40157 & 5110.9 & 3684.8 & -3683.8 \\
$\mathrm{~K}_{4-\text { Rqe2 }}$ & -23155 & 1584.6 & 2663.5 & -2691.3 \\
\hline
\end{tabular}

Table 6. Observer gains, with $a=0.3$. 
Common positive definite matrices that guarantees global asymptotic stability (Tanaka \& Wang, 2001), were found for each partial model, namely

$$
\begin{aligned}
P_{\mathrm{RF}} & =\left[\begin{array}{cccc}
1.6199 \times 10^{-4} & -3.8358 \times 10^{-5} & -3.5281 \times 10^{-5} & 3.44 \times 10^{-5} \\
-3.8358 \times 10^{-5} & 1.936 \times 10^{-5} & 4.2418 \times 10^{-6} & -4.1297 \times 10^{-6} \\
-3.5281 \times 10^{-5} & 4.2418 \times 10^{-6} & 1.094 \times 10^{-5} & -1.067 \times 10^{-5} \\
3.44 \times 10^{-5} & -4.1297 \times 10^{-6} & -1.067 \times 10^{-5} & 1.0781 \times 10^{-5}
\end{array}\right] ; \\
P_{\text {Rqe } 1} & =\left[\begin{array}{cccc}
1.0525 \times 10^{-3} & 1.6867 \times 10^{-5} & -4.4263 \times 10^{-5} & 4.2217 \times 10^{-5} \\
1.6867 \times 10^{-5} & 2.4884 \times 10^{-5} & -1.3321 \times 10^{-6} & 1.3043 \times 10^{-6} \\
-4.4263 \times 10^{-5} & -1.3321 \times 10^{-6} & 2.0592 \times 10^{-6} & -1.9649 \times 10^{-6} \\
4.2217 \times 10^{-5} & 1.3043 \times 10^{-6} & -1.9649 \times 10^{-6} & 2.3272 \times 10^{-6}
\end{array}\right] ; \\
P_{\text {Rqe2 }}= & {\left[\begin{array}{cccc}
1.7858 \times 10^{-3} & -3.6232 \times 10^{-4} & -3.4184 \times 10^{-4} & 3.3329 \times 10^{-4} \\
-3.6232 \times 10^{-4} & 0.00019792 \times 10^{-4} & 2.6424 \times 10^{-5} & -2.5682 \times 10^{-5} \\
-3.4184 \times 10^{-4} & 2.6424 \times 10^{-5} & 9.4507 \times 10^{-5} & -9.218 \times 10^{-5} \\
3.3329 \times 10^{-4} & -2.5682 \times 10^{-5} & -9.218 \times 10^{-5} & 9.4605 \times 10^{-5}
\end{array}\right] }
\end{aligned}
$$

From (58, 59 and 60) an exact fuzzy observer for a nonlinear baker's yeast model was designed. The fuzzy estimator had a satisfactory behavior. A different approach to construct a fuzzy observer using the whole term $O T R=K_{L} a\left(C^{\text {sat }}-x_{4}\right)$ as a known and constant perturbation was reported in (Herrera, 2007a). In this case a partial observer was constructed due that full rank in the observability matrix could not be achieved.

\section{The Fuzzy Exact Model, $(u(t)=D)$.}

The construction of the fuzzy exact model for a continuous baker's yeast fermentation can become quite complex when the output of the system is given by $u(t)=D$, for example for the $R F$ partial model

$$
\left[\begin{array}{c}
\dot{x}_{1} \\
\dot{x}_{2} \\
\dot{x}_{3} \\
\dot{x}_{4}
\end{array}\right]=\left[\begin{array}{cccc}
\mu_{s_{-} R F}^{o}+\mu_{s_{-} R F}^{r} & 0 & 0 & 0 \\
-k_{1} \mu_{s_{-} R F}^{o}-k_{2} \mu_{s_{-} R F}^{r} & 0 & 0 & 0 \\
k_{3} \mu_{s_{-} R F}^{r} & 0 & 0 & 0 \\
-k_{5} \mu_{s_{-} R F}^{o} & 0 & 0 & -K_{L} a
\end{array}\right]\left[\begin{array}{l}
x_{1} \\
x_{2} \\
x_{3} \\
x_{4}
\end{array}\right]+\left[\begin{array}{c}
-x_{1} \\
-x_{2}+S_{i n} \\
-x_{3} \\
-x_{4}
\end{array}\right] D+\left[\begin{array}{l}
0 \\
0 \\
0 \\
1
\end{array}\right] K_{L} a C^{s a t}
$$

In this case the input matrix is not constant anymore, depending now on the variables $x_{1}, x_{2}$, $x_{3}, x_{4}$. So we define the new premise variable as 


$$
z_{x_{1}}(t)=x_{1}, \quad z_{x_{2}}(t)=x_{2}, \quad z_{x 3}(t)=x_{3}, \quad z_{x 4}(t)=x_{4},
$$

The new premise variables may be written as

$$
\begin{array}{ll}
\varphi_{41}\left(z_{x 1}(t)\right)=\frac{z_{x 1}(t)-d_{2}}{d_{1}-d_{2}} & \varphi_{42}\left(z_{x 1}(t)\right)=\frac{-z_{x 1}(t)+d_{1}}{d_{1}-d_{2}} \\
\varphi_{51}\left(z_{x 2}(t)\right)=\frac{z_{x 2}(t)-e_{2}}{e_{1}-e_{2}} & \varphi_{52}\left(z_{x 2}(t)\right)=\frac{-z_{x 2}(t)+e_{1}}{e_{1}-e_{2}} \\
\varphi_{61}\left(z_{x 3}(t)\right)=\frac{z_{x 3}(t)-f_{2}}{f_{1}-f_{2}} & \varphi_{62}\left(z_{x 3}(t)\right)=\frac{-z_{x 3}(t)+f_{1}}{f_{1}-f_{2}} \\
\varphi_{71}\left(z_{x 4}(t)\right)=\frac{z_{x 4}(t)-g_{2}}{g_{1}-g_{2}} & \varphi_{72}\left(z_{x 4}(t)\right)=\frac{-z_{x 4}(t)+b_{1}}{b_{1}-b_{2}}
\end{array}
$$

where the maximum and minimum values of (63) are displayed in table 7.

\begin{tabular}{c|c|c}
\hline Premise variable & maximum & minimum \\
\hline$z_{x 1}(t)$ & $\mathrm{d}_{1}=10$ & $\mathrm{~d}_{2}=0$ \\
$z_{x 2}(t)$ & $\mathrm{e}_{1}=1$ & $\mathrm{e}_{2}=0$ \\
$z_{x 3}(t)$ & $\mathrm{f}_{1}=5$ & $\mathrm{f}_{2}=0$ \\
$z_{x 4}(t)$ & $\mathrm{g}_{1}=0.007$ & $\mathrm{~g}_{2}=0$ \\
\hline
\end{tabular}

Table 7. Maximum and minimum values for $z_{x 1}(t), z_{x 2}(t), z_{x 3}(t)$ and $z_{x 4}(t)$

The input matrix can now be written as

$$
B_{l m n o}=\left[-d_{l},-e_{m}+S_{i n},-f_{n},-g_{0}\right]^{T}
$$

The other premise variables are still given by (37) and (39). A general rule to construct all the fuzzy rules can be stated as

If $z_{1}(t)$ is " $\varphi_{1 i}\left(z_{1}(t)\right)$ " and $z_{2}(t)$ is " $\varphi_{2 j}\left(z_{2}(t)\right)$ " and $z_{x 1}(t)$ is " $\varphi_{4 l}\left(z_{2}(t)\right)$ " and $z_{x 2}(t)$ is " $\varphi_{5 m}\left(z_{2}(t)\right)$ " and $z_{x 3}(t)$ is " $\varphi_{6 n}\left(z_{2}(t)\right)$ " and $z_{x 4}(t)$ is " $\varphi_{70}\left(z_{2}(t)\right)$ "

$$
\text { THEN } \dot{x}^{R F}(t)=A_{i j l m n o}^{R F} x(t)+B_{i j l m n o} u(t)+d ; \quad \text { ijlmno }=1,2
$$

It must be remarked that 64 subsystems would be needed to construct the RF partial model. Finally the aggregated fuzzy system for the $R F$ partial model is given by 


$$
\begin{aligned}
& \dot{x}^{R F}(t)=\sum_{1}^{64} h_{\psi_{-} R F}(z(t))\left\{A_{i j l m n o}^{R F} x(t)+B_{i j l m n o}^{R F} u(t)+d\right\} \\
& y^{R F}(t)=\sum_{1}^{64} h_{\psi_{-} R F}(z(t)) C x(t), \quad \quad \text { ijlmno }=1,2 .
\end{aligned}
$$

where

$$
\begin{gathered}
\psi_{-R F}=o+2(n-1)+4(m-1)+8(l-1)+16(j-1)+32(i-1), \\
h_{\psi_{-} R F}(z(t))=h_{\psi_{-} R F}(z(t))=\varphi_{1 i}\left(z_{1}(t)\right) \varphi_{2 j}\left(z_{2}(t)\right) \varphi_{4 l}\left(z_{x_{1}}(t)\right) . \\
\varphi_{5 m}\left(z_{x_{2}}(t)\right) \varphi_{6 n}\left(z_{x_{3}}(t)\right) \varphi_{7 o}\left(z_{x_{4}}(t)\right)
\end{gathered}
$$

The $R_{q e 1}$ and $R_{q e 2}$ fuzzy exact model were constructed following the same rules and also 64 subsystems were obtained for each partial model. As stated before now the exact fuzzy model gets quite complex because it will be necessary 192 subsystems to represent the $R F$, $R_{q e 1}$ and $R_{q e 2}$ partial models. From the fuzzy exact model built for the case explained a fuzzy observer can also be built, more details are reported in (Herrera, 2007b). A multiple TakagiSugeno multiple controller was designed to force the switching between the $R F$ and the $\mathrm{R}$ baking yeast partial models (Herrera, 2007c; Herrera, 2007d). The substrate fuzzy controller tracked a square reference signal varied between $0.01 \mathrm{~g} / 1$ and $0.07 \mathrm{~g} / 1$. S in was set to $5 \mathrm{~g} / 1$.It is worth noting that the controller was capable to force the switching along the partial models.

\section{Conclusion}

Based on the idea of splitting the baker's yeast model, a novel TS fuzzy model was proposed using the sector nonlinearities method, giving an exact representation of the original nonlinear plant. Moreover, an observer for each partial model was constructed. It is worth noting that the observer was capable of switching along the partial models, without performance degradation. Therefore, the approach presented here may be considered a valid method to design an observer. Future work will include the experimental validation of the fuzzy observer and optimal controllers for fed-batch fermentation cultures.

\section{Acknowledgments}

This work has been supported by the Mexican Consejo Nacional de Ciencia y Tecnología (CONACyT), under grants 46538 and 41148.

\section{References}

Ascencio, P.; Sbarbaro, D. \& Azevedo, S. (2004). An adaptive fuzzy hybrid state observer for bioprocesses. IEEE Transactions on Fuzzy Systems, Vol. 12, No. 5, pp. 641-651, ISSN 1063-6706 
Bastin, G. \& Dochain, D. (1990). On Line Estimation and Adaptive Control of Bioreactors. Elsevier, ISBN 10-0-444-88430-0, Amsterdam

Braatz, R.; \& VanAntwerp (2000). A tutorial on linear and bilinear matrix inequalities. Journal of Process Control, Vol .10, pp. 363-385, ISSN 0959-1524

Cazzador, L. \& Luvenova, V. (1995). Nonlinear estimation of specific growth rate for aerobic fermentation processes. Biotechnology and Bioengineering, Vol. 47, pp. 626-632, ISSN 1097-0290

Chen, C. (1999). Linear Systems Theory and Design, Oxford University Press, ISBN 0030716918, United States of America

Dochain, D. (2003). State and parameter estimation in chemical and biochemical processes: a tutorial. Journal of Process Control, Vol. 13, pp. 801-818, ISSN 0959-1524

Farza, M.; Nadri, M. \& Hammouri, H. (2000). Nonlinear observation of specific growth rate in aerobic fermentation processes. Bioprocess Engineering, Vol. 23, pp. 359-366, ISSN $1615-7591$

Ferreira, E.C. (1995). Identificação e controlo adaptivo de processos biotecnológicos, $P h D$ Dissertation (in Portuguese), Universidade Do Porto

Genovesi, A.; Harmand, J. \& Steyer, J.P. (1999). A fuzzy logic based diagnosis system for the on-line supervision of an anaerobic digestor pilot-plant. Biochemical Engineering Journal, Vol. 3, No. 3, pp. 171-183, ISSN 1369-703X

Guay, M. \& Zhang, T (2002). Adaptive nonlinear observer for microbial growth processes. Journal of process control, Vol. 12, pp.633-643, ISSN 0959-1524

Herrera, L.; Castillo, T.; Ramírez, J. \& Ferreira, E.C. (2007a). Exact fuzzy observer for a baker's yeast fermentation process, 10th Computer Applications in Biotechnology, pp. 309-314, Cancún México, June 6-8, International Federation of Automatic Control, preprints, to be published at the IFAC-PapersOnLine website

Herrera, L.; Castillo, T.; Ramírez, J. \& Ferreira, E.C. (2007b). Exact fuzzy observer for a fedbatch baker's yeast fermentation process, IEEE International Conference on Fuzzy Systems, pp. 1-6. London England July 23-26, ISBN 1-4244-1210-2/07, IEEExplore ISSN 1098-7584

Herrera, L.; Castillo, T.; Ramírez, J. \& Ferreira, E.C. (2007c). Takagi-Sugeno multiple model controller for a continuous baking yeast fermentation process, $4^{\text {th }}$ International Conference on Informatics in Control, Automation and Robotics, pp. 436-439, Angers France, May 9-12, ISBN 978-972-8865-82-5

Herrera, L. (2007d). Sobre el problema de la observación y control de un modelo difuso para un proceso fermentativo conmutado, Ph. D. Thesis (In spanish), Centro de Investigación y de Estudios Avanzados del I.P.N, Unidad Guadalajara, México

Horiuchi, J. \& Kishimoto, M. (1998). Fuzzy-aided estimation of biological parameters based on material balances. Journal of Fermentation and Bioengineering, Vol. 86, pp. 111-117, ISSN 0922-338X

Karakazu, C.; Türker, M. \& Öztürk, S. (2006). Modeling, on-line state estimation and fuzzy control of production scale fed-batch baker's yeast fermentation. Control Engineering Practice, Vol. 14, No. 1, pp. 959-974, ISSN 0967-0661

Lubenova, V.; Rocha, I. \& Ferreira, E.C. (2003). Estimation of multiple biomass growth rates and biomass concentrations in a class of bioprocesses. Bioprocess Biosyst Eng, Vol. 25, pp. 395-406, ISSN: 1615-7591 
Oliveira, R.; Ferreira, E.C. \& Feyo de Azevedo, S. (2002). Stability dynamics of convergence and tuning of observer based kinetic estimators. Journal of Process Control, Vol. 12, pp. 311-323, ISSN 0959-1524

Pormeleau, P. (1990). Modelisation et controle d'un procéde fed-batch de culture des levures á pain (Saccharomyces cerevisiae). Ph. D. dissertation. Ecole Polytechnique de Montréal, Canada

Soh, Y.C. \& Cao, W. (1999). Multi-rate nonlinear state and parameter estimation in bioreactors. Biotechnology and Bioengineering, Vol. 63, No. 1, pp. 22-32, ISSN 10970290

Sonnleitner, B. \& Käppeli, O. (1986). Growth of Saccharomyces cerevisiae is controlled by its limited respiratory capacity: formulation and verification of a hypothesis. Biotechnology and Bioengineering, Vol. 28, pp. 927-937, ISSN 1097-0290

Takagi, T. \& Sugeno, M. (1985). Fuzzy identification of systems and its applications to modeling and control. IEEE trans. Sys. Man. Cyber., Vol. 15, pp. 116-132, ISSN 00189472

Tanaka, K. \& Wang, H. (2001). Fuzzy Control Systems Design and Analysis a Linear Matrix Inequality Approach, John Wiley \& Sons, ISBN 0-471-32324, United States of America

Veloso, C.; Rocha, I \& Ferreira, E.C. (2007) Estimation of biomass concentration using interval observer in an E. coli fed-batch fermentation, 10th Computer Applications in Biotechnology, pp. 99-104, Cancún México, June 6-8, International Federation of Automatic Control, preprints

Yamuna, R. \& Ramachandra, R. (1999). Control of fermenters - a review. Bioprocess Engineering, Vol. 21, pp. 77-88, ISSN 1615-7591 


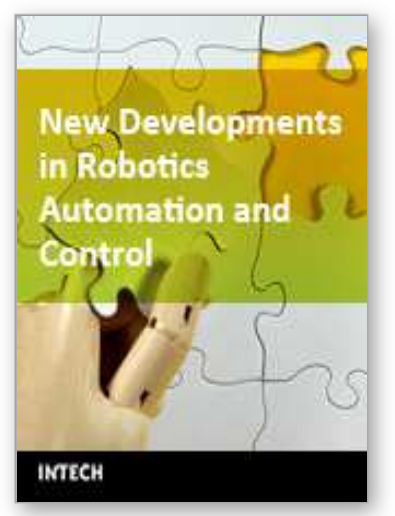

\section{New Developments in Robotics Automation and Control \\ Edited by Aleksandar Lazinica}

ISBN 978-953-7619-20-6

Hard cover, 450 pages

Publisher InTech

Published online 01, October, 2008

Published in print edition October, 2008

This book represents the contributions of the top researchers in the field of robotics, automation and control and will serve as a valuable tool for professionals in these interdisciplinary fields. It consists of 25 chapter that introduce both basic research and advanced developments covering the topics such as kinematics, dynamic analysis, accuracy, optimization design, modelling, simulation and control. Without a doubt, the book covers a great deal of recent research, and as such it works as a valuable source for researchers interested in the involved subjects.

\section{How to reference}

In order to correctly reference this scholarly work, feel free to copy and paste the following:

Enrique J. Herrera-Lopez, Bernardino Castillo-Toledo, Jesus Ramirez-Cordova and Eugenio C. Ferreira (2008). Takagi-Sugeno Fuzzy Observer for a Switching Bioprocess: Sector Nonlinearity Approach, New Developments in Robotics Automation and Control, Aleksandar Lazinica (Ed.), ISBN: 978-953-7619-20-6, InTech, Available from:

http://www.intechopen.com/books/new_developments_in_robotics_automation_and_control/takagisugeno_fuzzy_observer_for_a_switching_bioprocess_sector_nonlinearity_approach

\section{INTECH}

open science | open minds

\section{InTech Europe}

University Campus STeP Ri

Slavka Krautzeka 83/A

51000 Rijeka, Croatia

Phone: +385 (51) 770447

Fax: +385 (51) 686166

www.intechopen.com

\section{InTech China}

Unit 405, Office Block, Hotel Equatorial Shanghai

No.65, Yan An Road (West), Shanghai, 200040, China

中国上海市延安西路65号上海国际贵都大饭店办公楼 405 单元

Phone: +86-21-62489820

Fax: +86-21-62489821 
(C) 2008 The Author(s). Licensee IntechOpen. This chapter is distributed under the terms of the Creative Commons Attribution-NonCommercialShareAlike-3.0 License, which permits use, distribution and reproduction for non-commercial purposes, provided the original is properly cited and derivative works building on this content are distributed under the same license. 